\title{
Climate engineering and the ocean: effects on biogeochemistry and primary production
}

\author{
Siv K. Lauvset ${ }^{1}$, Jerry Tjiputra ${ }^{1}$, and Helene Muri ${ }^{2}$ \\ ${ }^{1}$ Uni Research Climate, Bjerknes Centre for Climate Research, Jahnebakken 5, Bergen, Norway \\ ${ }^{2}$ Department of Geosciences, Section for Meteorology and Oceanography, University of Oslo, Oslo, Norway
}

Correspondence: Siv K. Lauvset (siv.lauvset@uib.no)

Received: 6 June 2017 - Discussion started: 14 June 2017

Revised: 14 November 2017 - Accepted: 15 November 2017 - Published: 20 December 2017

\begin{abstract}
Here we use an Earth system model with interactive biogeochemistry to project future ocean biogeochemistry impacts from the large-scale deployment of three different radiation management (RM) climate engineering (also known as geoengineering) methods: stratospheric aerosol injection (SAI), marine sky brightening (MSB), and cirrus cloud thinning (CCT). We apply RM such that the change in radiative forcing in the RCP8.5 emission scenario is reduced to the change in radiative forcing in the RCP4.5 scenario. The resulting global mean sea surface temperatures in the RM experiments are comparable to those in RCP4.5, but there are regional differences. The forcing from MSB, for example, is applied over the oceans, so the cooling of the ocean is in some regions stronger for this method of RM than for the others. Changes in ocean net primary production (NPP) are much more variable, but SAI and MSB give a global decrease comparable to RCP4.5 ( 6\% in 2100 relative to 1971-2000), while CCT gives a much smaller global decrease of $\sim 3 \%$. Depending on the RM methods, the spatially inhomogeneous changes in ocean NPP are related to the simulated spatial change in the NPP drivers (incoming radiation, temperature, availability of nutrients, and phytoplankton biomass) but mostly dominated by the circulation changes. In general, the SAI- and MSB-induced changes are largest in the low latitudes, while the CCT-induced changes tend to be the weakest of the three. The results of this work underscore the complexity of climate impacts on NPP and highlight the fact that changes are driven by an integrated effect of multiple environmental drivers, which all change in different ways. These results stress the uncertain changes to ocean productivity in the future and advocate caution at
\end{abstract}

any deliberate attempt at large-scale perturbation of the Earth system.

\section{Introduction}

Human emissions of carbon dioxide to the atmosphere are unequivocally causing global warming and climate change (IPCC, 2013). At the 21st United Nations Framework Convention on Climate Change (UNFCCC) Conference of the Parties, it was agreed to limit the increase in global mean temperature to $2^{\circ} \mathrm{C}$ above preindustrial levels and to pursue efforts to remain below $1.5^{\circ} \mathrm{C}$. Reaching this goal will not be possible without radical social transformation. Solar radiation management (SRM) has been suggested as both a method of offsetting global warming and reducing the risks associated with climate change, substituting some degree of mitigation (Teller et al., 2003; Bickel and Lane, 2009), or buying time to reduce emissions (Wigley, 2006). Reducing the otherwise large anthropogenic changes in the marine ecosystem drivers (e.g., temperature, oxygen, and primary production) could also be beneficial for vulnerable organisms that need more time to migrate or adapt (Henson et al., 2017). SRM is an idea to increase the amount of solar radiation reflected by Earth in order to offset changes in the radiation budget due to the increased greenhouse effect from anthropogenic emissions, i.e., a form of climate engineering or geoengineering.

Here we have performed model experiments with stratospheric sulfur aerosol injections (Crutzen, 2006; Weisenstein et al., 2015), marine sky brightening (Latham, 1990), and cirrus cloud thinning (Mitchell and Finnegan, 2009) applied 
individually. Stratospheric aerosol injections (SAIs) would involve creating a layer of reflective particles in the stratosphere to reduce the amount of solar radiation reaching the surface. The most widely discussed approach to SAI is to release a gaseous sulfate precursor, like $\mathrm{SO}_{2}$, which would oxidize to form sulfuric acid and then condensate to reflective aerosol particles (e.g., Irvine et al., 2016). Marine sky brightening (MSB) aims to reflect the incoming solar radiation at lower levels in the atmosphere. Here, the idea is to spray naturally occurring sea salt particles into low-lying stratiform clouds over the tropical oceans to increase the available cloud condensation nuclei, thus increasing the concentration of smaller cloud droplets and the reflectivity of the clouds (Latham, 1990). The sea salt aerosols are reflective themselves (e.g., Ma et al., 2008), adding to the cooling potential of the method. Cirrus cloud thinning (CCT) on the other hand, aims to increase the amount of outgoing longwave radiation at the top of the atmosphere. This is envisioned by depleting the longwave trapping in high ice clouds by seeding them with highly potent ice nuclei (e.g., Mitchell and Finnegan, 2009; Storelvmo et al., 2013). In the absence of naturally occurring ice nuclei, the seeded material would facilitate freezing at lower supersaturations, enabling the growth of fewer and larger ice crystals. These would eventually grow so large that they sediment out of the upper troposphere, reducing the lifetime and optical thickness of the cirrus clouds and leading to a cooling effect. Together these three methods are referred to as radiation management (RM).

As pointed out by Irvine et al. (2017), there are several gaps in the research on the impact of RM on both the global climate and the global environment, especially considering that only a few modeling studies to date systematically compare multiple RM methods. Aswathy et al. (2015) and Niemeier et al. (2013) compared stratospheric sulfur aerosol injections to the brightening of marine clouds in terms of the hydrological cycle and extremes in temperatures and precipitation. Crook et al. (2015) compared the three methods used in this study, but restricted the study to temperatures and precipitation. This study focuses on the impact on the ocean carbon cycle, which could feed back to climate (Friedlingstein et al., 2006), in particular ocean primary production (NPP), which is known to be temporally and spatially complex.

The effect RM has on the ocean carbon cycle and ocean productivity has been studied previously, but limited to the use of simple one-dimensional models (Hardman-Mountford et al., 2013) or with global models but focusing on a single method of RM (Partanen et al., 2016; Tjiputra et al., 2016; Matthews et al., 2009). Due to the many uncertainties and open questions associated with RM impacts, a systematic comparative approach is necessary. The three different methods of RM used in this study are likely to have different effects on both the climate and the ocean due to the differences in the type of forcing being applied. A concern of RM is that it may allow for continued $\mathrm{CO}_{2}$ emissions in the future without the accompanied temperature increases and that it does not directly affect the atmospheric $\mathrm{CO}_{2}$ concentrations. Ocean acidification, a direct consequence of increased $\mathrm{CO}_{2}$ concentrations in the atmosphere, would therefore continue with RM unless paired with mitigation and/or carbon dioxide removal (CDR).

This paper is the first to evaluate and compare the effect and impact of multiple RM techniques on ocean biogeochemistry using a fully coupled state-of-the-art Earth system model and further extends previous studies by looking into impacts introduced by three different large-scale RM deployment scenarios both during and after the deployment periods. It is also the first study to assess the impacts of cirrus cloud thinning on ocean biogeochemistry. Our focus is the impacts on sea surface temperature (SST), oxygen, $\mathrm{pH}$, and NPP, which are the four climate drivers identified by the Intergovernmental Panel on Climate Change (IPCC) as significantly affecting marine ecosystem structure and functioning. In a wider perspective, ocean NPP is often used as an indicator for marine food availability, such as fisheries, so furthering our understanding has direct societal implications and a strong connection to the United Nations Sustainable Development Goals.

The model and experiments are described in detail in Sect. 2. The impacts on ocean temperature, oxygen content, the inorganic carbon cycle, and NPP are presented and discussed in Sect. 3, in addition to a comparison of our results to previous studies, while Sect. 4 summarizes and concludes the study.

\section{Methods}

\subsection{Model description}

Three RM methods were simulated using the Norwegian Earth system model (NorESM1-ME; Bentsen et al., 2013). The NorESM1-ME is a fully coupled climate-carbon cycle model that has contributed to the fifth assessment of the IPCC and participated in numerous Coupled Model Intercomparison Project phase 5 (CMIP5) analyses. For a full description of the physical and carbon cycle components of the model, the readers are referred to Bentsen et al. (2013) and Tjiputra et al. (2013), respectively. Here, we only briefly describe some key processes in the ocean carbon cycle that are relevant for this study.

The ocean carbon cycle component of the NorESM1ME originates from the Hamburg Oceanic Carbon Cycle Model (HAMOCC; Maier-Reimer et al., 2005). In the upper ocean, the lower trophic ecosystem is simulated using an NPZD-type (nutrient-phytoplankton-zooplankton-detritus) module. The NPP depends on phytoplankton growth and nutrient availability within the euphotic layer (for some of our calculations assumed to be $100 \mathrm{~m}$ ). In addition to multinutrient limitation, phytoplankton growth is light and tem- 
perature dependent. The NPP in NorESM1-ME is parameterized using the equations of Six and Maier-Reimer (1996) (Eq. 1):

$G=r(T, L) \times \frac{N}{N+N_{0}}$,

where $G$ is the growth rate and

$r(T, L)=\frac{f(L) \times f(T)}{\sqrt{ }\left(f(L)^{2}+f(T)^{2}\right)}$.

$N$ is the concentration of the limiting nutrient (either phosphate, nitrate, or dissolved iron), $N_{0}$ is the half-saturation constant for nutrient uptake, $f(L)$ is the function determining light dependency, and $f(T)$ is the function for temperature dependency. Both $f(L)$ and $f(T)$ were defined in Six and Maier-Reimer (1996).

$\mathrm{NPP}=G \times P$

NPP is the net primary production and $P$ is the phytoplankton concentration.

In addition to the growth through NPP, phytoplankton have several sink terms due to mortality, exudation, and zooplankton grazing. All nutrients, plankton, and dissolved biogeochemical tracers are prognostically advected by the ocean circulation. The model adopts generic bulk phytoplankton and zooplankton compartments. The detritus is divided into organic and inorganic materials: particulate organic carbon, biogenic opal, and calcium carbonate. Organic carbon, once exported out of the euphotic layer, is remineralized at depth - a process that consumes oxygen in the ocean interior. Nonremineralized particles reaching the sea floor undergo chemical reactions with sediment pore water, bioturbation, and vertical advection within the sediment module. The model calculates air-sea $\mathrm{CO}_{2}$ fluxes as a function of seawater solubility, gas transfer rate, and the gradient of the gas partial pressure $\left(\mathrm{pCO}_{2}\right)$ between the atmosphere and the ocean surface, following Wanninkhof (1992). Prognostic surface ocean $\mathrm{pCO}_{2}$ is computed using inorganic seawater carbon chemistry formulation following the Ocean Carbon-Cycle Model Intercomparison Project (OCMIP2).

In this study, we made use of ocean NPP simulated by the NorESM1-ME (hereafter referred to as "online calculations") and calculations using the monthly averaged model outputs (hereafter referred to as "offline calculations"). The offline calculations also made use of Eqs. (1)-(3), the same as the model, but unlike in the model (i) the average value over the top $100 \mathrm{~m}$ was used for $N, T$, and $P$ alike. (ii) $L$ was approximated as incident light at the surface attenuated to a constant depth of $50 \mathrm{~m}$, and (iii) the monthly mean was used for $N, T, L$, and $P$. The choice of attenuation depth for the light has a small but not significant effect on the results. Averaging the light input over the top $100 \mathrm{~m}$ does, however, yield the same results as using an attenuation depth of
$50 \mathrm{~m}$. The offline calculations allowed us to decompose and identify the dominant drivers of the simulated changes. The decomposition was done by choosing to keep all but one parameter, $x$, constant at a time to quantify the contribution of $x$ to the total change. Table 1 describes how this was done. The parameters being kept constant were kept at the long-term (80-year) monthly mean, as calculated from the preindustrial model experiment (with constant atmospheric $\mathrm{CO}_{2}$ concentrations).

\subsection{Experiment setup}

SAI, MSB, and CCT were applied individually to the RCP8.5 (representative concentration pathway) future scenario (Table 2). The target of the simulations was to reduce the global mean top of the atmosphere (TOA) radiative flux imbalance of RCP8.5 down to RCP4.5. In each experiment, the forcing is applied over the years 2020 to 2100 . To study the termination effect, the simulations were continued for another 50 years following the cessation of each RM method. Here, the SAI, MSB, and CCT experiments are analyzed and compared to the RCP4.5 and RCP8.5 scenarios (Riahi et al., 2011; Thomson et al., 2011) (Table 2). All simulations were run with interactive biogeochemistry and used prescribed anthropogenic $\mathrm{CO}_{2}$ emissions. The atmospheric $\mathrm{CO}_{2}$ concentrations are therefore prognostically simulated accounting for land-air and sea-air $\mathrm{CO}_{2}$ fluxes.

As the NorESM1-ME model does not include an interactive aerosol scheme in the stratosphere, the dataset of Niemeier and Timmreck (2015) was used to implement the SAI. The stratospheric zonal mean sulfate aerosol extinction, single-scattering albedo, and asymmetry factors resulting from $\mathrm{SO}_{2}$ injections in the tropics were prescribed such that the prescribed aerosol layer in the year 2100 corresponds to an $\mathrm{SO}_{2}$ injection strength of $40 \mathrm{Tg} \mathrm{SO}_{2} \mathrm{yr}^{-1}$ (Muri et al., 2017). The MSB follows the method of Alterskjær et al. (2013) in which the emissions of "accumulation mode" sea salt were increased over the oceans. Here we chose to apply this to a latitude band of $\pm 45^{\circ}$. The tropospheric aerosol scheme is fully prognostic, thus allowing for the full interactive cycle with clouds and radiation. As for the CCT, we adopted the approach of Muri et al. (2014), where the terminal velocity of ice crystals at typical cirrus-forming temperatures colder than $-38^{\circ} \mathrm{C}$ is increased. The maximum effective radiative forcing was found to be limited at about $-3.8 \mathrm{~W} \mathrm{~m}^{-2}$ for CCT, resulting in a somewhat higher top of the atmosphere (TOA) radiative flux imbalance in this simulation at 2100 compared to the other simulations in which an effective radiative forcing of $-4.0 \mathrm{~W} \mathrm{~m}^{-2}$ in 2100 was reached. 
Table 1. Description of the offline calculations of ocean NPP and primary drivers using Eqs. (1)-(3). $T$ is the average temperature in the top $100 \mathrm{~m}, L$ is shortwave radiation attenuated to $50 \mathrm{~m}$ of depth, $N$ is the concentration of the limiting nutrient (either nitrate, phosphate, or dissolved iron) in the top $100 \mathrm{~m}$, and $P$ is the concentration of phytoplankton cells in the top $100 \mathrm{~m}$. $\overline{\mathbf{X}}$ denotes the long-term (80-year) mean of the given variable.

\begin{tabular}{ll}
\hline Calculation & \\
\hline $\mathrm{NPP}_{\text {total }}$ Everything changes & $T, L, N, P$ \\
$\mathrm{NPP}_{\text {temp }}$ Only temperature changes & $T, \bar{L}, \bar{N}, \bar{P}$ \\
$\mathrm{NPP}_{\text {light }}$ Only shortwave radiation changes & $L, \bar{T}, \bar{N}, \bar{P}$ \\
$\mathrm{NPP}_{\text {residual }}$ & $\mathrm{NPP}_{\text {total }}-\mathrm{NPP}_{\text {temp }}-\mathrm{NPP}_{\text {light }}$ \\
\hline
\end{tabular}

Table 2. General description of the model experiments used in this study.

\begin{tabular}{|c|c|c|}
\hline Experiment & Description & Time period \\
\hline $\mathrm{RCP} 4.5$ & Reference RCP4.5 scenario & $2006-2100$ \\
\hline RCP8.5 & Reference RCP8.5 scenario & $2006-2150$ \\
\hline SAI & $\begin{array}{l}\text { RCP8.5 scenario with a layer of sulfate particles is prescribed } \\
\text { in the stratosphere to reflect incoming shortwave radiation and } \\
\text { bring down global average temperatures }\end{array}$ & $2020-2100$ \\
\hline SAIEXT & $\begin{array}{l}\text { The extension of the SAI run after termination of climate engi- } \\
\text { neering in } 2100\end{array}$ & $2101-2150$ \\
\hline MSB & $\begin{array}{l}\text { RCP } 8.5 \text { scenario in which salt particles are emitted at the sea } \\
\text { surface between } 45^{\circ} \mathrm{S} \text { and } 45^{\circ} \mathrm{N} \text { to make both the sky and } \\
\text { clouds brighter, thus increasing the Earth's albedo and thereby } \\
\text { lowering global average temperatures }\end{array}$ & $2020-2100$ \\
\hline $\mathrm{MSB}_{\mathrm{EXT}}$ & $\begin{array}{l}\text { The extension of the MSB run after termination of climate en- } \\
\text { gineering in } 2100\end{array}$ & $2101-2150$ \\
\hline $\mathrm{CCT}$ & $\begin{array}{l}\text { RCP8.5 scenario in which cirrus clouds are thinned out; cirrus } \\
\text { clouds have a net heating effect so fewer ice clouds will result } \\
\text { in lower global average temperatures }\end{array}$ & $2020-2100$ \\
\hline $\mathrm{CCT}_{\mathrm{EXT}}$ & $\begin{array}{l}\text { The extension of the CCT run after termination of climate engi- } \\
\text { neering in } 2100\end{array}$ & $2101-2150$ \\
\hline
\end{tabular}

\section{Results and discussion}

\subsection{Global changes in ocean temperature and oxygen concentration}

Relative to the 1971-2000 historical period, the ocean oxygen content in the $200-600 \mathrm{~m}$ depth interval is projected to decrease by $\sim 6 \%$ globally in 2100 in RCP8.5 (Fig. 1a). In RCP4.5 on the other hand, the oxygen inventory in the $200-600 \mathrm{~m}$ interval shows only a minor decrease of $2 \%$ by 2100 (Fig. 1a). This difference stems partly from lower oxygen solubility as the ocean warms and partly from changes in ocean stratification and circulation (not shown). When applying RM to RCP8.5, the oxygen concentration in this depth interval follows the RCP4.5 development closely for all three RM methods (ranging from a 2-2.6\% decrease in 2100 compared to the 1971-2100 average). There are, however, differences between the methods, with SAI yielding slightly larger decreases after 2060 (Fig. 1a). After termination of $\mathrm{RM}$, the rate of oxygen reduction accelerates rapidly for the first 10 years before stabilizing at a new rate of decrease of similar magnitude to that in RCP8.5. The projected oxygen reductions do not drop as low as in RCP8.5 after termination of the RM during our simulation period, but had the simulations been continued for some further decades, the oxygen levels would most likely have converged to the RCP8.5 levels. In 2150, RCP8.5 shows a global mean oxygen decrease globally of $9.5 \%$, while the simulations with terminated RM show a global mean oxygen decrease of 8-8.5\% (Fig. 1a).

In RCP8.5, the global mean SST is projected to increase by $\sim 2.5^{\circ} \mathrm{C}$ by 2100 relative to 2010 (Fig. 1b) and $\sim 3{ }^{\circ} \mathrm{C}$ relative to the 1971-2000 average. With $\mathrm{RM}$, the changes in SST are kept similar to RCP4.5, with an increase ranging from 0.8 to $1.1^{\circ} \mathrm{C}$ over the time period between 2020 (start of RM deployment) and 2100 (end of RM deployment). After termination, there is a very rapid SST increase in the subsequent decade before the SST increases more gradually towards that in RCP8.5. Similar to the development in oxygen content, the absolute change in SST in the model runs with terminated RM is still smaller than the absolute change in RCP8.5 (Fig. 1b) in 2150. This is mainly due to the slow response time of the ocean, so the SST would eventually con- 

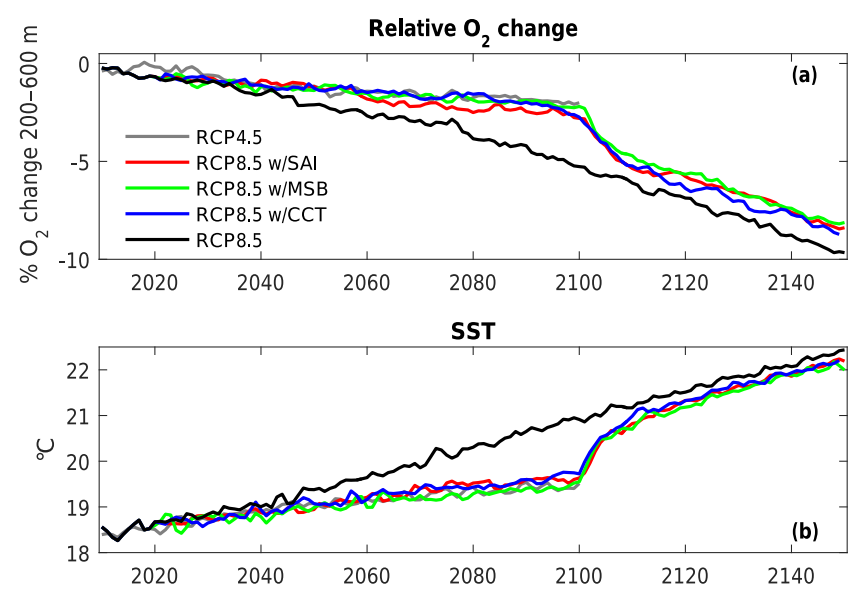

Figure 1. Time series of global average change in (a) oxygen content at $200-600 \mathrm{~m}$ of depth $(\%)$ and (b) SST $\left({ }^{\circ} \mathrm{C}\right)$. The oxygen change is relative to the 1971-2000 average in the historical run.

verge had the simulations been carried out for a longer period of time after termination. It should be noted that all methods of RM used in this study have been implemented to produce the global mean radiative forcing at the end of the century that is equivalent to offsetting the difference in the anthropogenic radiative forcing between RCP8.5 and RCP4.5, i.e., $-4 \mathrm{~W} \mathrm{~m}^{-2}$. This means that the globally averaged sea surface temperature changes, and changes in large-scale physically driven variables such as oxygen are expected to be close to those in RCP4.5. The results presented here imply that applying RM does not prevent the long-term impacts of climate change, which is also not expected as long as $\mathrm{CO}_{2}$ emissions are not simultaneously reduced, but would on average delay them. In the case of oxygen concentrations in the 200-600 m depth interval, the changes incurred in RCP4.5 and when the three different methods of RM are applied are mostly not significantly different from the 1971-2000 average (i.e., they are smaller than 1 standard deviation of the 1971-2000 mean; Fig. 2). There are a few exceptions in which the oxygen changes are significant. These regions, however, highlight how differently the RM methods affect the ocean.

The spatial distribution of absolute change in SST in 2071-2100 relative to 1971-2000 is shown in Fig. 3b for RCP8.5 and Fig. 3c for RCP4.5. The changes are significantly smaller in RCP4.5, but the spatial variations are the same in RCP8.5 and RCP4.5. When applying RM, the changes in SST are smaller everywhere than in RCP8.5 at the end of the century. Similar to thermocline oxygen, the SST changes are altered in some regions, as seen in the zonally averaged temperature changes (Fig. 3a). The SAI method yields the temperature change most similar to that in RCP4.5, which is also mirrored in the near-surface air temperatures (Muri et al., 2017). MSB yields the SST changes that are most different compared to RCP4.5. For this method there is a strong bimodal pattern in the SST changes in the North Pacific
(Fig. 3e), which is also seen in oxygen (Fig. 2e). The tropical and subtropical changes in SST with MSB are linked to an enhancement of the Pacific Walker cell, which is induced when MSB is applied as has been found in previous studies such as Bala et al. (2011), Alterskjær et al. (2013), Ahlm et al. (2017), Stjern et al. (2017), and Muri et al. (2017).

Regardless of the RM method, some regions, in particular the northwestern Pacific, will still experience levels of warming (cooling) and oxygen loss (gain) exceeding those in RCP4.5. With SAI, the North American west coast, which is an important region for aquaculture, will experience enhanced deoxygenation, which is not projected to happen in RCP4.5. The large spatial heterogeneity in how RM affects ocean temperatures and oxygen concentrations highlights the fact that RM can still lead to similar, albeit weaker, detrimental conditions regionally even if they are beneficial in the global mean.

\subsection{Global changes in the inorganic ocean carbon cycle}

The atmospheric $\mathrm{CO}_{2}$ concentration continues to rise in all experiments in which RM is applied at a similar rate as in RCP8.5 (Fig. 4a) given no simultaneous mitigation efforts in these cases. The atmospheric $\mathrm{CO}_{2}$ concentration in 2100 in RCP8.5 is 1109 ppm and in 2150 it is $1651 \mathrm{ppm}$. In 2100 there is a minor reduction in $\mathrm{CO}_{2}$ concentrations when $\mathrm{RM}$ is applied of 13-21 ppm compared to RCP8.5 depending on method. MSB gives the largest decrease in atmospheric $\mathrm{CO}_{2}$. The termination of RM does not significantly affect the atmospheric $\mathrm{CO}_{2}$ evolution and in 2150 there is a marginal reduction of -15 to $-26 \mathrm{ppm}$ depending on method, again with MSB giving the largest reduction. The reductions in atmospheric $\mathrm{CO}_{2}$ concentrations when applying RM are due to the decreasing ocean temperatures leading to a larger airsea flux of $\mathrm{CO}_{2}$ (Fig. 4b). Note that the land carbon sinks also increase slightly when RM is applied (Tjiputra et al., 2016; Muri et al., 2017). The lower $\mathrm{CO}_{2}$ concentration with MSB is due to the forcing from MSB being applied over the oceans and the cooling of the ocean in many regions thus being stronger for this method of RM (Fig. 3e).

While RM leads to a small increase in global mean oceanic $\mathrm{CO}_{2}$ uptake from the atmosphere due to increased solubility, the difference introduced by each method is not outside of the interannual variability of RCP8.5 up to 2075 . By 2100 , the different $\mathrm{RM}$ methods give an additional $\mathrm{CO}_{2}$ uptake of $\sim 0.5 \mathrm{Pg} \mathrm{Cyr}^{-1}$. After termination, the uptake anomaly quickly drops and returns to the same level as RCP8.5 within only 2 years. Future surface ocean $\mathrm{pH}$ is forced by the increasing atmospheric $\mathrm{CO}_{2}$ concentrations, which drive the uptake of $\mathrm{CO}_{2}$ in the surface ocean. Thus RM could possibly worsen future ocean acidification unless atmospheric $\mathrm{CO}_{2}$ concentrations are dealt with. However, given the small changes in both atmospheric concentrations and ocean uptake stemming from $\mathrm{RM}$, the surface $\mathrm{pH}$ is not greatly af- 


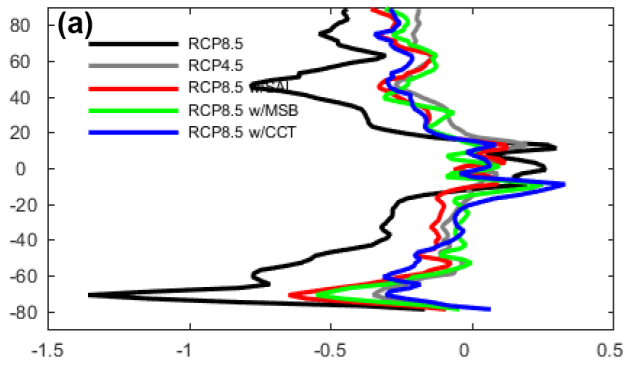

(c) RCP4.5

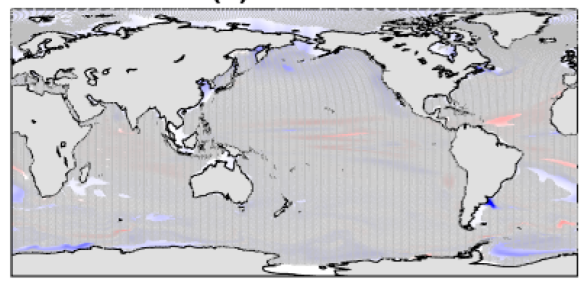

\section{(b) RCP8.5}

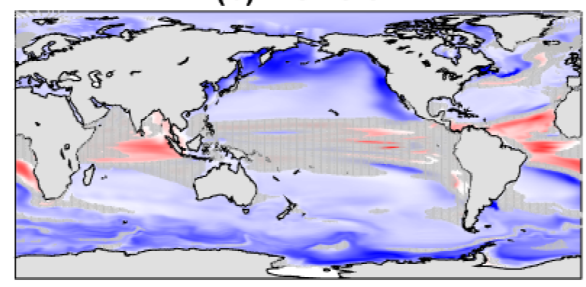

(d) RCP8.5 w/SAI

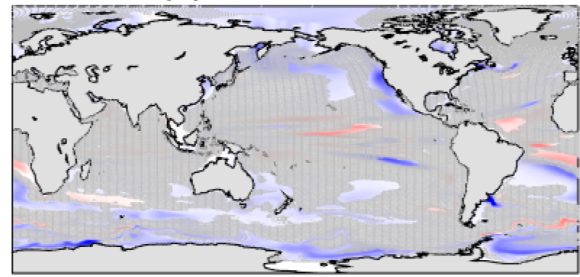

(e) RCP8.5 w/MSB

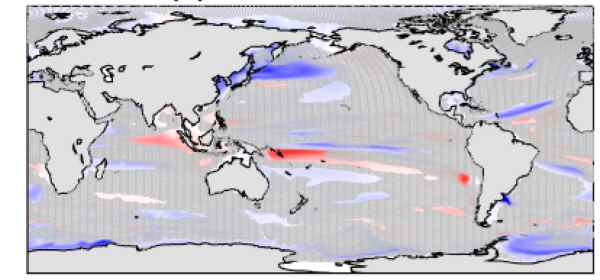

(f) RCP8.5 w/CCT

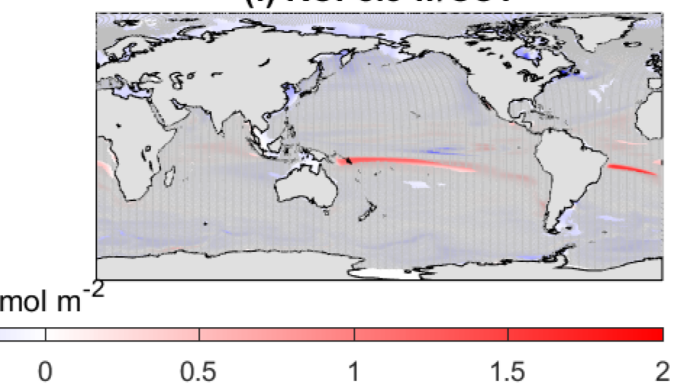

Figure 2. The absolute change in oxygen concentration $\left(200-600 \mathrm{~m}\right.$ ) in 2071-2100 relative to 1971-2000 (in $\mathrm{moles}_{2} \mathrm{~m}^{-2}$ ). Panel (a) shows zonally averaged (in $2^{\circ}$ latitude bands) change for all simulations. Global maps of (b) RCP8.5, (c) RCP4.5, (d) RCP8.5 with SAI, (e) RCP8.5 with MSB, and (f) RCP8.5 with CCT. Gray shading in panels (b-f) indicates areas where the change is not significantly different from the 1971-2000 average (i.e., within 1 standard deviation of the 1971-2000 mean).

fected by RM (Fig. 4c). Hence, termination does not considerably affect the $\mathrm{pH}$ decrease on the surface ocean.

Anthropogenic changes in the ocean inorganic carbon content come from the top down, so it takes a long time for these changes to be observable in the deep ocean. Therefore, the globally averaged deep ocean $(>2000 \mathrm{~m}$ ) $\mathrm{pH}$ changes by only $0.06 \mathrm{pH}$ units between 2010 and 2150 in RCP8.5 (Fig. 4d). The only region where $\mathrm{pH}$ changes significantly in the deep ocean is the North Atlantic north of $30^{\circ} \mathrm{N}$ where the strong overturning circulation brings anthropogenic carbon to great depths in a relatively short timeframe. Here there is a significant decrease in deep ocean $\mathrm{pH}$ between 2010 and 2150 in RCP8.5 and the three RM cases (Fig. 4e). In RCP8.5, the $\mathrm{pH}$ is projected to decrease by $\sim 0.2 \mathrm{pH}$ units in 2100 . RM leads to an additional acidification of 0.02-0.045 (depending on the method of RM) in the deep North Atlantic Ocean, which is large enough to marginally but not significantly affect the global average (Fig. 4d). A similar result was found by Tjiputra et al. (2016). After termination of RM, the
$\mathrm{pH}$ keeps decreasing - now at a rate comparable to RCP8.5. This change in the rate of decrease after termination happens within $\sim 10$ years, indicating that the changes in the inorganic carbon cycle are very quick in the North Atlantic. Both the rapid decrease in deep ocean $\mathrm{pH}$ in this region and the rapid recovery towards RCP8.5 development after termination of RM are likely linked to changes in the Atlantic Meridional Overturning Circulation due to climate change and RM (not shown; see Muri et al., 2017). While the global mean $\mathrm{pH}$ below $2000 \mathrm{~m}$ in RM experiments rebounds to that of the RCP8.5, this is not the case for the North Atlantic. In the latter, all RM methods lead to and remain at lower $\mathrm{pH}$ than the RCP 8.5 by 2150. It is possible that the deep pH in the North Atlantic would recover to that in RCP8.5 had the simulations been continued for another few decades. 


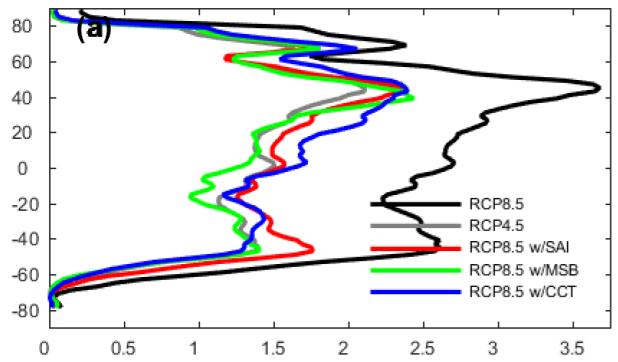

(c) RCP4.5

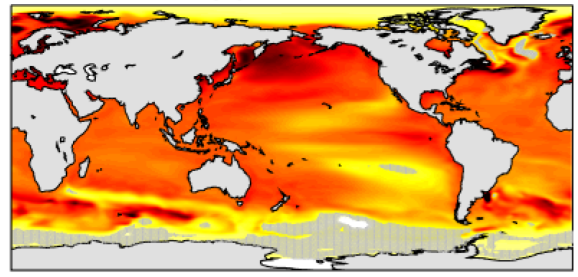

(e) RCP8.5 w/MSB

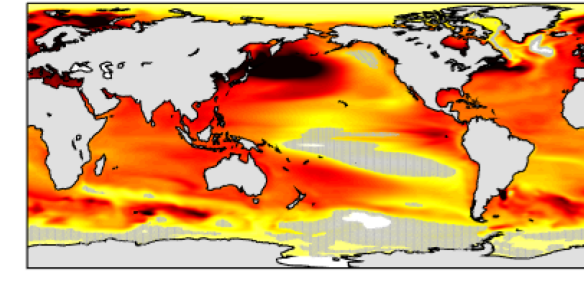

${ }^{\circ} \mathrm{C}$

\section{(b) RCP8.5}

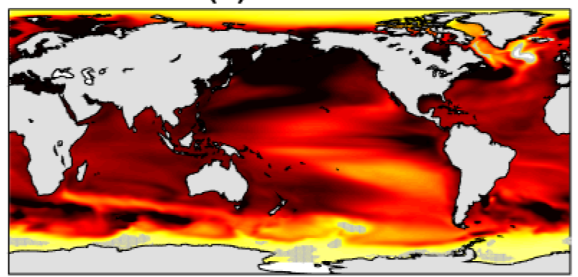

(d) RCP8.5 w/SAI

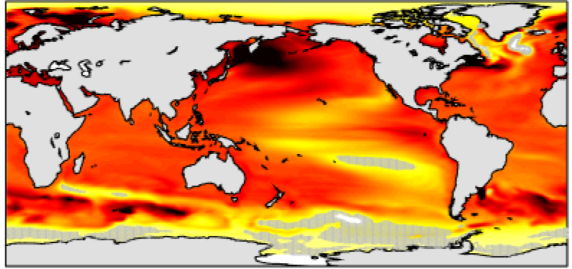

(f) RCP8.5 w/CCT

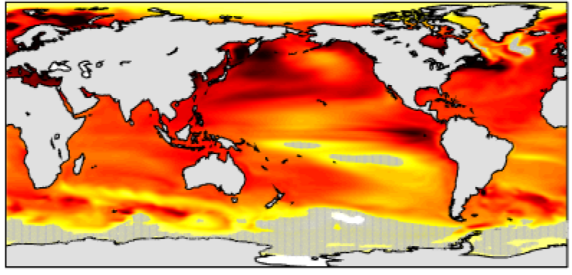

Figure 3. The absolute change in sea surface temperature (SST) in 2071-2100 relative to 1971-2000 (in ${ }^{\circ} \mathrm{C}$ ). Panel (a) shows zonally averaged (in $2^{\circ}$ latitude bands) change for all simulations. Global maps of (b) RCP8.5, (c) RCP4.5, (d) RCP8.5 with SAI, (e) RCP8.5 with MSB, and (f) RCP8.5 with CCT. Gray shading in panels (b-f) indicates areas where the change is not significantly different from the 1971-2000 average (i.e., within 1 standard deviation of the 1971-2000 mean).

\subsection{Global changes in ocean NPP}

The direct effects of RM on surface shortwave radiation and temperature directly affect photosynthesis through the light and temperature dependence of the phytoplankton growth rate. The ocean productivity, and by extension ocean biological carbon pump, is thus indirectly affected by RM. There is a lot of interannual variability in the NPP changes, and hence Fig. 5 shows the 5-year running averages of relative changes to the 1971-2000 average. In RCP8.5, there is a decrease in global NPP of $\sim 10 \%$ by 2100 (Fig. 5), which is within the range of the decrease projected by CMIP5 models of $-8.6 \pm 7.9 \%$ (Bopp et al., 2013) and mainly due to the overall warming leading to a more stratified ocean in which there are less nutrients available in the euphotic zone. All RM methods also exhibit decreases in ocean NPP, but the decrease is never as strong as that in RCP8.5. The shortwavebased methods, i.e., SAI and MSB, that reduce the amount of downward solar radiation at the surface have the largest decreases $(\sim 6 \%$ in 2100$)$ of the RM methods, which is a stronger decrease than in RCP4.5. The longwave-based CCT method, however, yields only a minor decrease of $\sim 3 \%$ in 2100 , i.e., less than in RCP4.5. As the cirrus clouds are thinned or removed, more sunlight reaches the surface ocean, thus promoting and increasing NPP above the RCP4.5 levels.

The fact that CCT shows a significant global increase in ocean NPP relative to RCP8.5 and even an increase relative to RCP4.5 is a very interesting result of this study. It suggests that when considering the global ocean NPP changes alone, the implementation of CCT may offer the least negative impact of the three tested methods. The side effect, however, is that if terminated suddenly at a large-scale deployment with no simultaneous mitigation or CDR efforts, the CCT method would lead to the most drastic change in NPP over a very short period. The divergence between methods is particularly strong in the period $2070-2100$ as the radiative forcing by $\mathrm{RM}$ approaches $-4 \mathrm{~W} \mathrm{~m}^{-2}$. After termination, it takes less than 5 years for the ocean NPP to return to RCP8.5 levels 

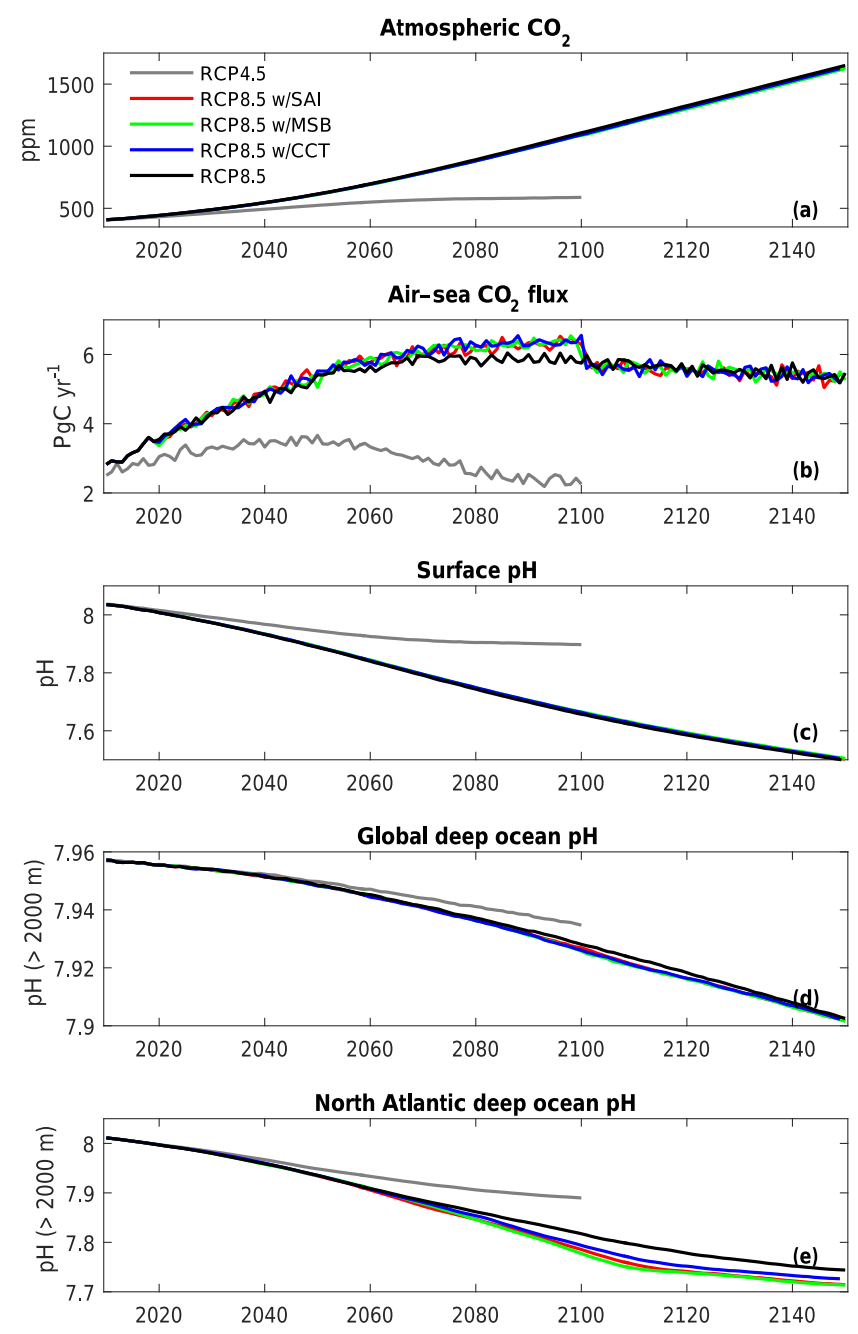

Figure 4. Time series of global average change in (a) atmospheric $\mathrm{CO}_{2}$ (ppm), (b) air-sea $\mathrm{CO}_{2}$ flux $\left(\mathrm{PgC} \mathrm{yr}^{-1}\right)$, (c) global surface ocean $\mathrm{pH}$, (d) global deep ocean $(>2000 \mathrm{~m}) \mathrm{pH}$, and (e) deep $\left(>2000 \mathrm{~m}\right.$ ) North Atlantic Ocean (north of $30^{\circ} \mathrm{N}$ ) pH.

again. This is consistent with the rapid warming seen after termination (Fig. 1b) and is driven by the fast atmospheric response to the termination.

On average there are some interesting spatial features in how NPP changes. Figure 6a shows the zonally averaged difference between 2071-2100 and 1971-2000. In the Northern Hemisphere, NPP decreases everywhere and decreases less in RCP4.5 and with RM than in RCP8.5. In the Southern Hemisphere, on the other hand, the changes in NPP are much more spatially variable, and the response to the different methods of RM is more variable. Between the Equator and $40^{\circ} \mathrm{S}$ there is a reduction in NPP in 2071-2100 relative to $1971-2000$, while south of $40^{\circ}$ there is generally an increase (except in a narrow band at $60^{\circ} \mathrm{S}$ ). In the Southern Hemisphere the impact of CCT is quite different from the impact of SAI and MSB. This is probably due to the

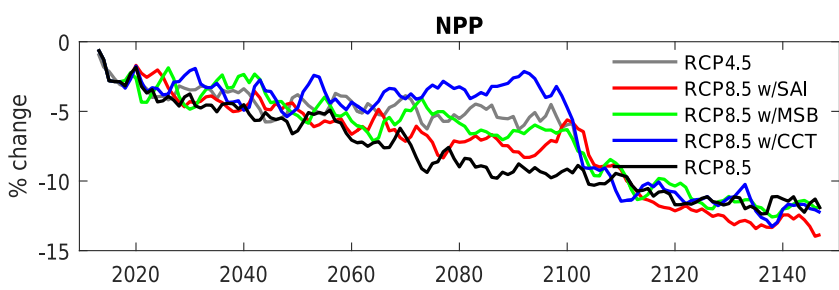

Figure 5. Time series of changes in global ocean NPP (\%). The NPP change is relative to the 1971-2000 average in the historical run.

change in radiative balance, which is much stronger for CCT in the southern high latitudes than for the other methods (not shown; see Muri et al., 2017). Because of the large spatial and interannual variability, the changes incurred to ocean NPP in the future are frequently not significantly different from the 1971-2000 average (i.e., the absolute change is smaller than 1 standard deviation of the 1971-2000 mean; Fig. 6bf). This means that when RM is applied, the ocean NPP does not change in most of the ocean. However, it is clear that the changes in NPP in 2071-2100 relative to 1971-2000 are smaller in RCP4.5 than in RCP8.5 (Fig. $6 \mathrm{~b}$ and c) and that the spatial variations in all experiments mainly come from the nutrient availability (not shown), which is furthermore dependent on ocean stratification. There are also some regions of significant change in ocean NPP, which are discussed further in Sect. 3.5.

\subsection{Drivers of global changes in ocean NPP}

To further evaluate how RM affects ocean NPP, we have made offline calculations using Eqs. (1)-(3). From the NorESM1-ME model outputs we used the monthly mean nitrate, phosphate, iron, and phytoplankton concentration over the top $100 \mathrm{~m}$, the average temperature in the top $100 \mathrm{~m}$, and shortwave radiation input attenuated to $50 \mathrm{~m}$ of depth. The resulting offline NPP is therefore an approximation of the NPP in the top $100 \mathrm{~m}$ of the ocean. The offline global average is $75 \%$ of the full water column NPP inventory as simulated by the model, and spatially the offline-calculated NPP is larger than the model output in oligotrophic regions and smaller than the model output in coastal and upwelling regions as expected (not shown). In addition, the temporal rate of change is somewhat smaller for the offline-calculated NPP (not shown). Note that the following results and discussion concerns only the offline NPP calculations and therefore only the top $100 \mathrm{~m}$ of the ocean. The offline calculation shows that in the top $100 \mathrm{~m}$ only CCT significantly changes $\mathrm{NPP}_{\text {total }}$ compared to RCP8.5. In fact, CCT results in an increased productivity by 2100 (Fig. 7a) in the offline calculation, which is linked to the increase in the incoming solar radiation in some regions, since the shortwave reflection from ice clouds is reduced. After termination of CCT, the 


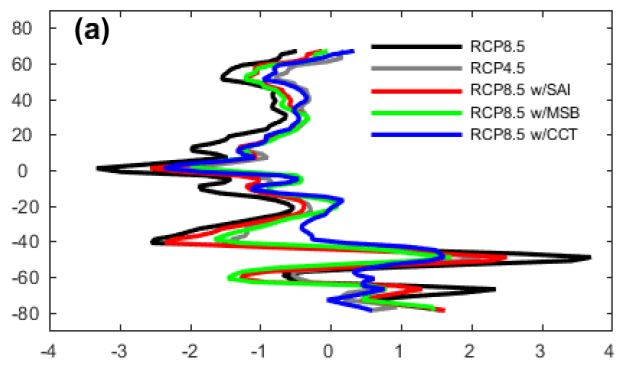

(c) RCP4.5

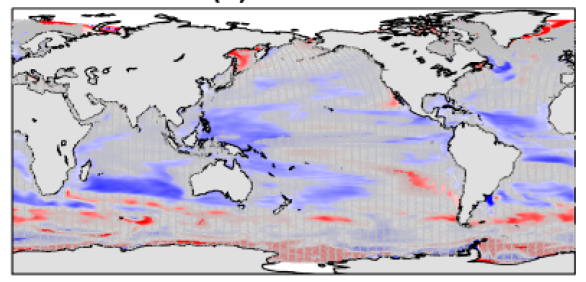

(e) RCP8.5 w/MSB

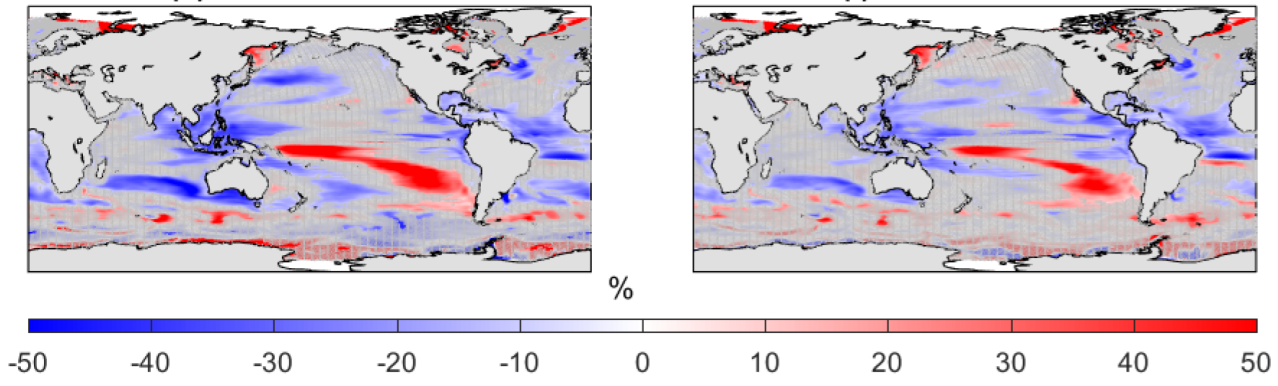

(b) RCP8.5

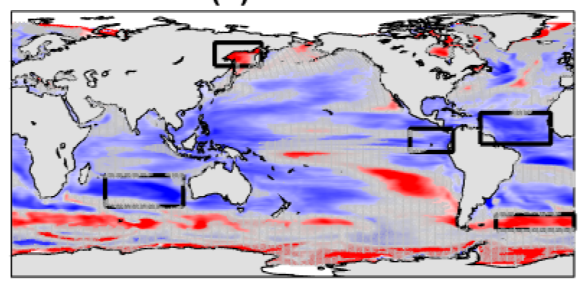

(d) RCP8.5 w/SAI

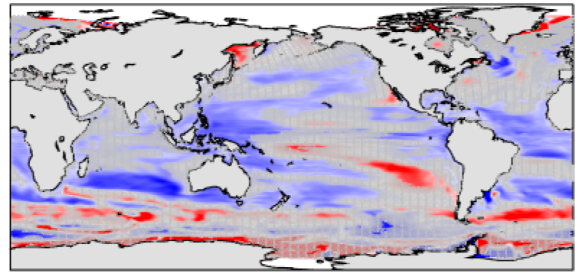

(f) RCP8.5 w/CCT

Figure 6. The percent changes in NPP in 2071-2100 relative to the $1971-2000$ average in the historical run. (a) Zonally averaged (in $2^{\circ}$
latitude bands) change for all simulations. (b) RCP8.5, (c) RCP4.5, (d) RCP8.5 with SAI, (e) RCP8.5 with MSB, (f) RCP8.5 with CCT. Gray shading in panels (b-f) indicates areas where the change is not significantly different from the 1971-2000 average (i.e., within 1 standard deviation of the 1971-2000 mean). The outlined areas in panel (b) indicate regions plotted in Fig. 9.

$\mathrm{NPP}_{\text {total }}$ drops to the same level as RCP8.5 within 2 years. The RCP4.5 scenario yields little change by 2100 .

Warmer temperatures increase growth rates. Thus when only temperature is allowed to change, $\mathrm{NPP}_{\text {temp }}$ increases in the offline calculation (Fig. 7b), as temperature increases in all scenarios considered here (Fig. 1b), even though the increase is less in simulations with RM than RCP8.5. All methods of RM yield an increase in $\mathrm{NPP}_{\text {temp }}$ of $\sim 1 \%$ from 2020 to 2100, which is comparable to RCP4.5. This is consistent with SST being comparable between RCP4.5 and RM (Fig. 1b). After termination, $\mathrm{NPP}_{\text {temp }}$ increases rapidly for the first 5 years before stabilizing with the same rate of change as that in RCP8.5. Just like SST (Fig. 1b), the absolute change in $\mathrm{NPP}_{\text {temp }}$ does not quite recover to the same absolute level as that in RCP8.5, but all simulations show an increase in $\mathrm{NPP}_{\text {temp }}$ of $\sim 3 \%$ by 2150 .

Reduced shortwave radiation at the surface decreases growth rates and thus leads to decreased NPP. In RCP4.5 and RCP8.5, light constraints do not change much, and hence when using the output from these experiments and only shortwave radiation changes in the offline calculation, $\mathrm{NPP}_{\text {light }}$ does not considerably change (Fig. 7c). Both SAI and MSB decrease the amount of global mean direct shortwave radiation at the surface, however, which negatively affects the phytoplankton growth rate and $\mathrm{NPP}_{\text {light }}$ in the ocean (Fig. 7c). The result is therefore a decrease in $\mathrm{NPP}_{\text {light }}$ of $\sim 2 \%$ by 2100 for SAI and MSB (Fig. 7c). When reducing the optical thickness and the lifetime of the cirrus clouds in the model, the shortwave reflection by these clouds is reduced, allowing more shortwave radiation to reach the surface and increasing the growth rate. CCT thus results in an increase in $\mathrm{NPP}_{\text {light }}$ of $\sim 2 \%$ by 2100 (Fig. 7c). It is this increase in available shortwave radiation that causes the majority of the increase in ocean productivity with CCT, with some contribution from the elevated temperatures (Fig. 7b). Within 2 years of the termination of RM, the NPP light has completely returned to the baseline conditions. 

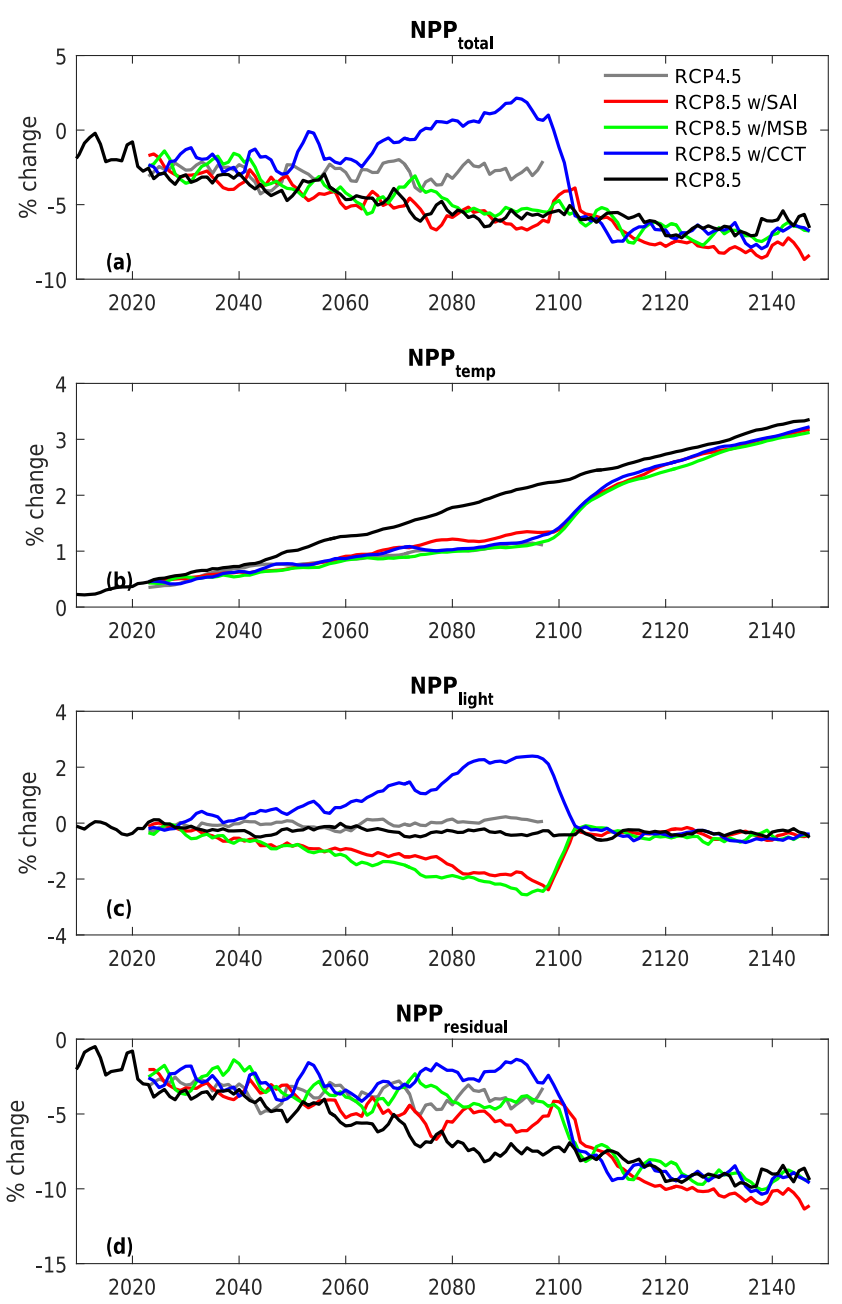

Figure 7. Time series of the 5-year running mean of globally averaged NPP (\%) calculated offline using Eqs. (1)-(3) and plotted as the percent change relative to the 1971-2000 average in the historical run. The residual $\left(\mathrm{NPP}_{\text {total }}-\mathrm{NPP}_{\text {temp }}-\mathrm{NPP}_{\text {light }}\right)$ represents the circulation-induced changes. Note the different scales on the $y$ axes. See Table 1 for an explanation of the different calculations shown.

There cannot be any growth of phytoplankton without nutrients. However, changes in the concentration of the limiting nutrient (either phosphate, nitrate, or dissolved iron) have a small effect on the growth rate (not shown). NPP is the product of growth rate and phytoplankton concentration (Eq. 2), but phytoplankton concentration is also a function of growth rate, grazing, aggregation, and mortality. In the model, the time step is small and the relationships are fully dynamic within the NPZD framework. However, since we use monthly model output in the offline calculation, the phytoplankton concentration is not independent of either the nutrient availability or the growth rate. Therefore we look at the residual $\mathrm{NPP}_{\text {residual }}$ $\left(\mathrm{NPP}_{\text {total }}-\mathrm{NPP}_{\text {temp }}-\mathrm{NPP}_{\text {light }}\right)$. This residual approximates the integrated circulation-induced changes in phytoplankton concentration and the concentration of the limiting nutrient. The latter is an important limiting factor for NPP, especially in the low-latitude regions, and is largely influenced by circulation changes. Figure $7 \mathrm{~d}$ shows that $\mathrm{NPP}_{\text {residual }}$ dominates over the growth rate in determining changes in ocean NPP. Overall, NPP residual accounts for a decrease of $\sim 8 \%$ by 2100 in RCP8.5. The SAI and MSB methods of RM also exhibit a change in $\mathrm{NPP}_{\text {residual }}$, but the change of $\sim 5 \%$ is less than that in RCP8.5. With CCT there is no significant change in $\mathrm{NPP}_{\text {residual }}$ by 2100 relative to $1971-2000$. After termination, NPP residual decreases rapidly and after 4-5 years it continues changing at a rate comparable to that in $\mathrm{RCP} 8.5$, reaching a global mean reduction greater than $-10 \%$ in 2150 .

\subsection{Regional changes in ocean NPP}

As seen in Fig. 6, the projected changes in ocean NPP exhibit large spatial variation. These spatial patterns are comparable to the NPP calculated offline (Fig. 8). Applying RM does not change the large-scale spatial heterogeneity, but rather works to enhance or weaken the change magnitude (Figs. 6 and 8 ). These regional differences are important, since regional changes are much more important than global changes when determining the impact ocean NPP has on human food security (Mora et al., 2013). For a more detailed analysis, five regions have been identified and analyzed using the offline calculations of NPP and its drivers. These regions are chosen based on the following:

i. a significant change, i.e., outside of \pm 1 standard deviation, in NPP in RCP8.5 in years $2071-2100$ relative to 1971-2000;

ii. the sign of the change in ocean NPP projected by NorESM1-ME being consistent with that of the CMIP5 models ensemble mean (Bopp et al., 2013; Mora et al., 2013);

iii. the impact the different methods of RM has on this increase or decrease in the online simulations; and

iv. their relative importance for fish catches, as identified in Zeller et al. (2016).

The regions are outlined in black in Fig. $6 \mathrm{~b}$ and labeled as the Equatorial Pacific, Equatorial Atlantic, Southern Atlantic, Indian Ocean, and Sea of Okhotsk in Fig. 9. In RCP8.5, the Sea of Okhotsk and the Southern Atlantic exhibit a significant increase in NPP in 2071-2100 relatively to 1971-2000, while the Equatorial Pacific, Indian Ocean, and Equatorial Atlantic show a significant weakening (Fig. 9).

The IPCC Assessment Report 5 (AR5) states that due to lack of consistent observations, it remains uncertain how the future changes in marine ecosystem drivers (like productivity, acidification, and oxygen concentrations) will alter the higher trophic levels (Pörtner et al., 2014). Given the lack 


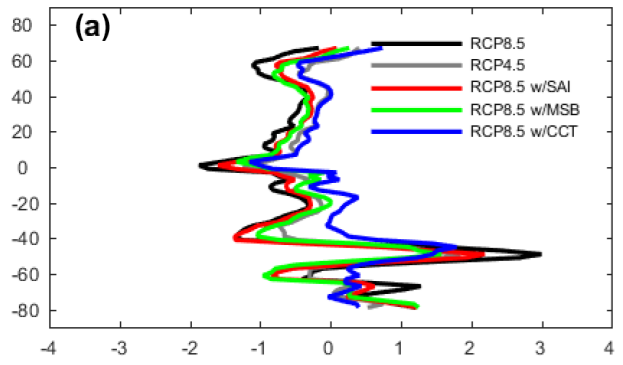

(c) RCP4.5

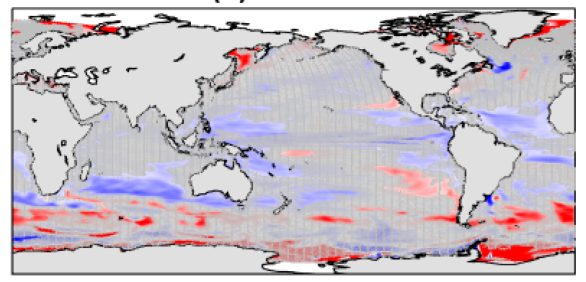

(e) RCP8.5 w/MSB

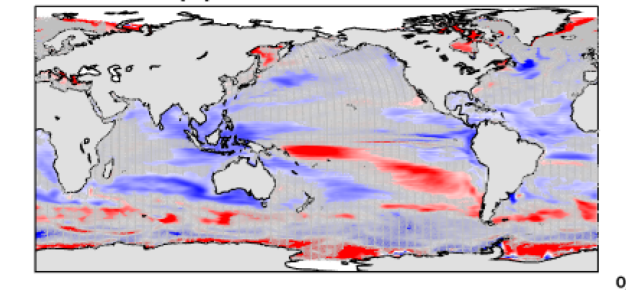

$\%$

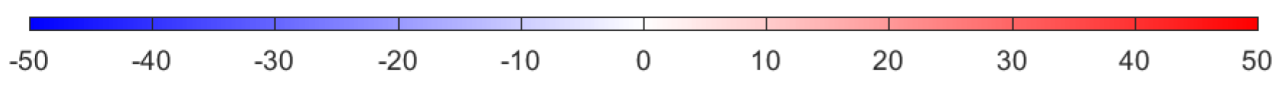

(b) RCP8.5

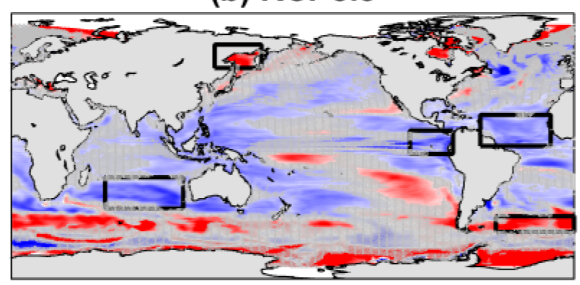

(d) RCP8.5 w/SAI

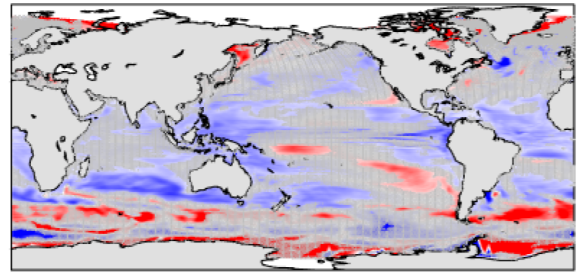

(f) RCP8.5 w/CCT

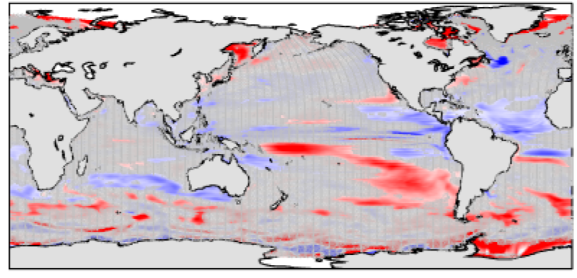

50

Figure 8. The percent change in the offline-calculated NPP in 2071-2100 relative to the 1971-2000 average in the historical run. (a) Zonally averaged (in $2^{\circ}$ latitude bands) change for all simulations. (b) RCP8.5, (c) RCP4.5, (d) RCP8.5 with SAI, (e) RCP8.5 with MSB, (f) RCP8.5 with CCT. Gray shading in panels (b-f) indicates areas where the change is not significantly different from the 1971-2000 average (i.e., within 1 standard deviation of the 1971-2000 mean). The outlined areas in panel (b) indicate regions plotted in Fig. 9.

of complexity and lack of higher trophic level organisms in the NorESM1-ME, we are unable to directly link changes in NPP to impacts on the higher tropic levels in this study. It therefore cannot be assumed from our results that increased NPP will lead to increased fish stocks and thus the potential for higher fish catches because the driving factors leading to higher NPP (i.e., temperature, light availability, and stratification) could also lead to biodiversity changes. Given the changes in Arctic biodiversity observed today due to temperature changes (e.g., Bucholz et al., 2012; Fossheim et al., 2015), respective changes in migration patterns would be likely to happen also with RM. Nevertheless, higher NPP does lead to more food for higher trophic level organisms; therefore a significant decrease in regional NPP could decrease higher tropic organisms due to less food availability in those regions. Based on the model projections, it is possible that there will be fewer fish catches in the Indian Ocean and Equatorial Atlantic in the future than today. The different methods of RM also lead to different effects on ocean NPP
(Figs. 6 and 9). Only in the Equatorial Atlantic and in the shaded regions where there are no significant changes do all three methods give changes in NPP comparable to those in RCP4.5.

In the Equatorial Pacific, RCP8.5 leads to a decrease in ocean NPP of $-21 \%$ in 2071-2100 relative to 1971-2000 driven by circulation-induced changes in phytoplankton concentration and nutrient availability. Circulation-induced changes dominate the change of $-12 \%$ in RCP4.5 too. This region is today a very productive fishery area (Zeller et al., 2016), so a significant decrease in NPP could have adverse effects on fish catches. It is therefore noteworthy that all RM methods yield NPP changes only marginally smaller than those in RCP8.5 and not nearly as small as those in RCP4.5. When RM is applied, shortwave radiation changes at the surface become more important in driving NPP changes than they are in RCP8.5 and RCP4.5, which is consistent with changes in cloud fraction (not shown; see Muri et al., 2017). With CCT, the radiation changes yield an increase in NPP of 

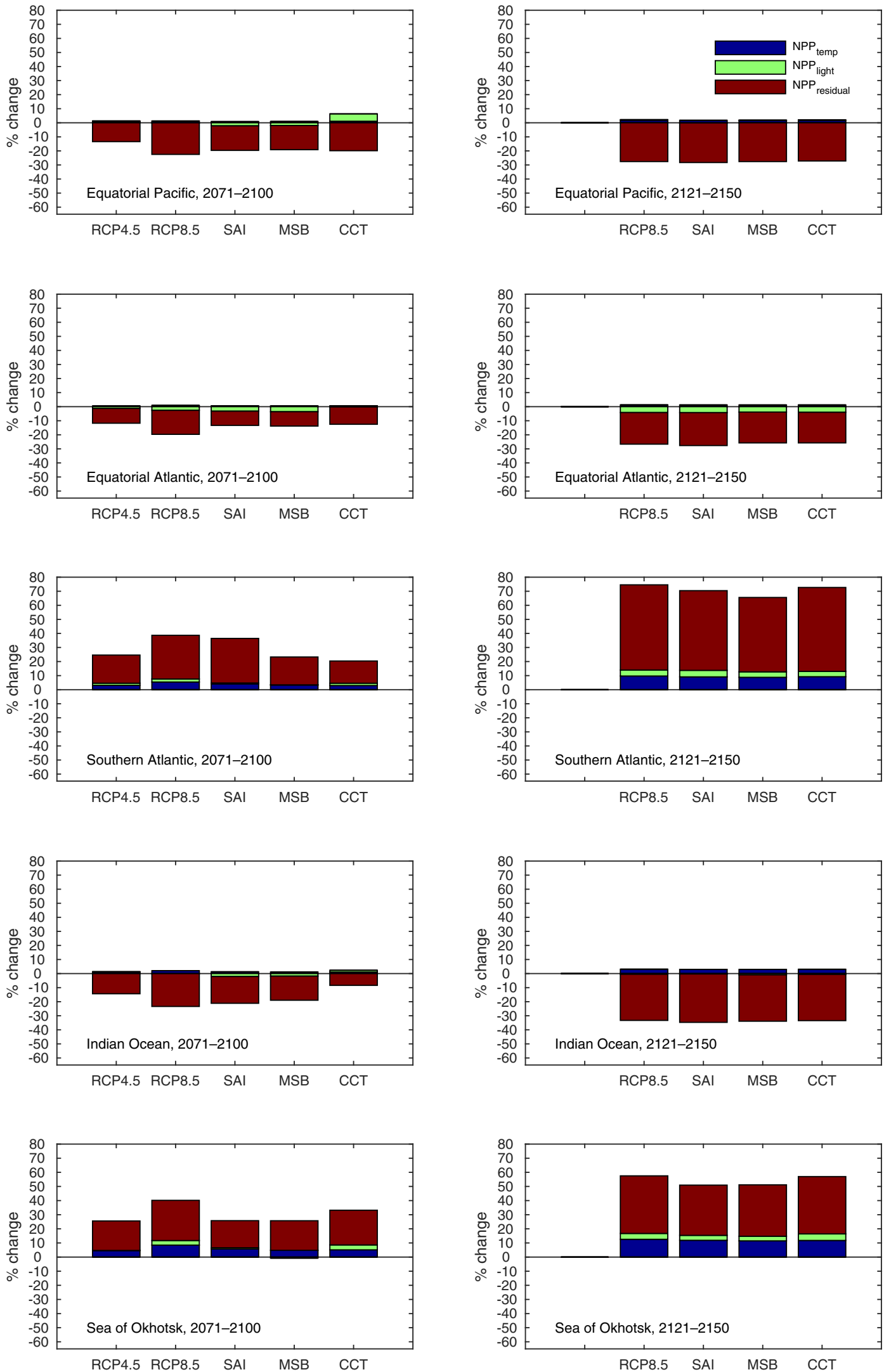

Figure 9. Offline-calculated NPP change (\%) in five different regions (as indicated in Fig. 6b) for RCP4.5, RCP8.5, and RCP8.5 with three different $\mathrm{RM}$ methods. The residual $\left(\mathrm{NPP}_{\text {total }}-\mathrm{NPP}_{\text {temp }}-\mathrm{NPP}_{\text {light }}\right)$ represents the circulation-induced changes. 
$5 \%$, indicating that this is one of the regions that drive the global mean increase in NPP (Fig. 7a). After termination, the change in NPP is comparable to that in RCP8.5 in all experiments, and the warming results in a small increase in NPP of $\sim 2 \%$ (Fig. $7 b$ ).

The Southern Atlantic has the largest changes in 20712100 relative to 1971-2000; RCP8.5 results in an increase in ocean NPP of $39 \%$ and RCP4.5 leads to an increase of $25 \%$. SAI leads to changes in NPP comparable to that in RCP8.5, while MSB and CCT yield changes more in line with RCP4.5. For all experiments, the circulation-induced changes are the dominant factor. Changes in temperatures contribute $\sim 5 \%$ to the total change, which is consistent with a significant warming in all experiments (Fig. 3). This alleviates the temperature limitation of the growth rate, which is consistent with the other CMIP5 models (Bopp et al., 2013). After termination, the increase continues in the Southern Atlantic, and in 2121-2150 the changes in NPP are 60-70\% higher than in 1971-2000 in all experiments.

As in all other regions, in the Sea of Okhotsk the circulation-induced changes dominate. SAI and MSB both yield changes comparable to those in RCP4.5, while CCT, on the other hand, is comparable to RCP8.5. In all experiments, temperature changes are an important driver of the overall increases in NPP, which is consistent with the strong warming in this region (Fig. 3). After termination, all experiments yield comparable increases in NPP, with a very strong contribution from the temperature changes.

In the Equatorial Atlantic, there is a reduction of ocean NPP in RCP8.5 of $-19 \%$ in 2071-2100 relative to 19712000. Circulation-induced changes dominate this change, with a minor negative contribution of $<5 \%$ from radiation changes. All methods of RM yield changes in ocean NPP more in line with those in RCP4.5 $(-11 \%)$, but changes in radiation are more important with SAI and MSB. After termination, all experiments result in the same decrease in ocean NPP of $-25 \%$.

In the Indian Ocean, there is also a reduction of ocean NPP in RCP8.5. Here the total change in $2071-2100$ is $-21 \%$, but unlike in any other regions the temperature-induced changes lead to only a small increase of $1-2 \%$ in all experiments. This is consistent with parts of this region experiencing only a small increase in SST (Fig. 3). Both SAI and MSB yield changes in NPP comparable to those in RCP8.5 $(-19$ and $-18 \%$ respectively), but changes in radiation contribute $\sim-2 \%$ to the total reduction. There is, however, no corresponding change in cloud cover (see Muri et al., 2017) to explain the apparent importance of radiation changes in this region. The Indian Ocean is also one of the regions where CCT is able to sustain (i.e., induce the fewest changes in) the contemporary NPP. After termination, the ocean NPP continues to decrease and in $2121-2150$ is $30 \%$ lower than in 1971-2000 in all experiments.

\subsection{Comparison with previous studies}

Very few other studies have been published on the impact on ocean biogeochemistry due to RM. One such study is by Hardman-Mountford et al. (2013), which used a onedimensional water column model to study the effect of reduced light availability on phytoplankton growth. Their results imply that even a significant reduction $(90 \%)$ of solar radiation barely affects total column biological productivity, but can considerably alter the vertical distribution of productivity. However, their study did not consider how other processes, such as local cooling or the horizontal transport of nutrients, would affect the marine ecosystems, and their simplistic model setup was also unable to capture broader effects on the ocean carbon cycle. The magnitude of regional changes in NPP found in this study differs from the results of Hardman-Mountford et al. (2013), but the NPP changes seen in the oligotrophic gyres are very small and not statistically significant. Given the very large differences in method, no in-depth comparison of this study and Hardman-Mountford et al. (2013) has been undertaken. Two other recent studies, which are both more comparable to this one, are Tjiputra et al. (2016) and Partanen et al. (2016). Tjiputra et al. (2016), who used the same model as in this study, identified changes in ocean NPP and export production in a simulation with SAI. The implementation of SAI is somewhat different here, both in methodology and magnitude of forcing, but the spatial pattern and sign of surface climate response and the overall impact on global ocean NPP are broadly consistent. Nevertheless, our study provides a more extended and in-depth analysis based on different RM methods and identifies the dominant drivers of changes in NPP in key ocean regions. Partanen et al. (2016), on the other hand, analyzed the effects on ocean NPP from marine cloud brightening (MCB) only. Overall, the effects in this study and that of Partanen et al. (2016) are quite different. Spatially, Partanen et al. (2016) see a very strong correlation between the regions where the cloud brightening forcing was applied and the regions of strongest NPP change, which is not apparent in this study. Temporally, the change in NPP in Partanen et al. (2016) comes in the form of a relatively rapid decrease over the first 10 years when the cloud brightening forcing is applied, while in this study the change is more even throughout the period of MSB forcing. This is likely due to the several noteworthy differences between their method and the one used here.

i. Partanen et al. (2016) use the UVic ESCM model, an Earth system model of intermediate complexity (EMIC), while here we use the fully coupled NorESM1-ME Earth system model.

ii. Here, we increase oceanic sea salt emissions over $\pm 45^{\circ}$ latitude, not only brightening the marine stratocumulus decks, but also reflecting more shortwave radiation with the increase in bright aerosols through the direct effect. Partanen et al. (2016), on the other hand, pre- 
scribe changes in radiation over three marine stratocumulus areas inferred from model output from Partanen et al. (2012).

iii. The RM forcing applied by Partanen et al. (2016) is $-1 \mathrm{~W} \mathrm{~m}^{-2}$ annually, while here it is ramped up to $-4 \mathrm{~W} \mathrm{~m}^{-2}$ in 2100 .

iv. Partanen et al. (2016) apply RM to RCP4.5, while here we apply RM to RCP8.5.

v. Partanen et al. (2016) apply RM for 20 years before termination, while here we apply RM for 80 years before termination; combined with the higher forcing, this means that the Earth system takes longer to recover in this study than in the Partanen et al. (2016) study.

The biggest and most important of these differences is that Partanen et al. (2016) use an EMIC, while we use an ESM with the forcing applied over a much larger area. NorESM1ME has a fully interactive tropospheric aerosol scheme accounting for both the direct and the indirect effects of the aerosols, which is of key importance when evaluating the impact of changes in shortwave radiation reaching the surface from changes to clouds. Partanen et al. (2016) take their forcing from Partanen et al. (2012), which uses an atmosphereonly version of their model and hence neglects important feedbacks, including SST and ocean feedbacks. Partanen et al. (2016) furthermore prescribe their forcing in terms of changes to the radiation, and hence miss out on further feedbacks with their one-layered atmosphere with prescribed circulation, which are processes that are much more comprehensively represented in our fully coupled Earth system model. MSB may, for example, lead to an increased sinking of air over the oceans and hence a reduction in cloud cover, as seen in Ahlm et al. (2017), Stjern et al. (2017), and Muri et al. (2017). The ecosystem module in NorESM1-ME is not substantially more complex than that of the UViC ESCM model, but differences could arise due to better representation of the ocean physical circulation (owing to higher spatial resolution) and air-sea interactions. Partanen et al. (2016) identify a decrease in global mean ocean NPP relative to their reference case (RCP4.5), while in our MSB simulation we simulate an increase in ocean NPP relative to our reference case (RCP8.5). This likely impacts the differences in results since the global mean and rate of change of ecosystem drivers in RCP4.5 are smaller than RCP8.5 (Henson et al., 2017). These methodological differences and the large differences in the spatial impact can partly be explained by the differences in the applied RM forcing and method, but is mostly explained by the fundamental differences between the models. Another important difference between Partanen et al. (2016) and this study is the timing of termination, since this is a very important aspect of all climate engineering studies. Partanen et al. (2016) apply RM for 20 years before termination, while we apply RM for 80 years before termina- tion. This means that in our study the impact on temperature and ocean circulation is greater than in the Partanen et al. (2016) study, as the slow climate feedbacks are allowed to pan out. This could explain the differences in termination effect between the studies in which the NPP fully recovers and exceeds that in RCP4.5 in the Partanen et al. (2016) study, but remain within the variability of RCP 8.5 here. The larger magnitude of the forcing applied in our simulations $\left(-4 \mathrm{~W} \mathrm{~m}^{-2}\right.$ in 2100$)$ also means that it takes much longer for the climate system to recover to the RCP8.5 state.

\section{Conclusions}

In this study, we use the Norwegian Earth system model with a fully interactive carbon cycle to assess the impact of three radiation management (RM) climate engineering methods on marine biogeochemistry. The model simulations indicate that RM may reduce perturbations in SST and thermocline oxygen driven by anthropogenic climate change, but that large changes in NPP remain and are even intensified in some regions. It must be noted that we use only one model and that such models are known to have large spread in their projections of future ocean NPP (e.g., Bopp et al., 2013). However, this single-model study does show some clear tendencies.

i. A clear mitigation of the global mean decrease in ocean NPP from $10 \%$ in 2100 in RCP8.5 and 5\% in RCP4.5 to somewhere between 3 and $6 \%$, depending on the method of RM.

ii. Strong regional variations in the changes and what primarily drives the changes in ocean NPP. The different methods of RM do not have the same effects in the same regions, even though SAI and MSB yield similar global averages.

iii. Spatially MSB yields the largest changes relative to RCP4.5, which is consistent with MSB being applied over the ocean, and therefore likely affects the ocean more strongly than the other methods.

The effect of future climate change on ocean NPP is uncertain and is driven by an integrated change in physical factors, such as temperature, radiation, and ocean mixing. Additionally, changes in ocean oxygen concentrations and ocean acidification are likely to affect ocean NPP. It is noteworthy that with RM as the scenario is designed in this study, anthropogenic $\mathrm{CO}_{2}$ emissions are not curbed, so ocean acidification would continue. The results presented in this study show that future changes to ocean NPP would likely be negative on average, but exhibit great variation both temporally and spatially regardless of whether or not RM is applied.

This study also shows that for the first 5 to 10 years after a sudden termination of large-scale RM with no mitigation or CDR efforts, the SST, oxygen, surface $\mathrm{pH}$, and NPP all experience changes that are significantly larger than those 
projected without RM implementation or mitigation. While there is still large uncertainty in how marine habitats respond to such rapid changes, it is certain than they would have less time to adapt or migrate to a more suitable location and would potentially face a higher likelihood of extinction if RM was suddenly halted during large-scale deployment with no mitigation.

The results of this work do nothing to diminish the complexity of climate impacts on NPP, but rather highlight the fact that any change in ocean NPP is driven by a combination of several variables that all change in different ways in the future and are subsequently affected differently when RM is applied. The importance of ocean NPP for human societies, however, lies in its impact on food security in general and fisheries in particular, for which regional changes are much more important than global changes (Mora et al., 2013).

Data availability. All model data are available upon request to the corresponding author.

Competing interests. The authors declare that they have no conflict of interest.

Special issue statement. This article is part of the special issue "Progress in quantifying ocean biogeochemistry - in honour of Ernst Maier-Reimer". It is not associated with a conference.

Acknowledgements. The authors acknowledge funding from the Norwegian Research Council through the project EXPECT (229760). We also acknowledge NOTUR resource NN9182K and Norstore NS9033K and NS1002K. Helene Muri was also supported by RCN project 261862/E10, 1.5C-BECCSy. Jerry Tjiputra also acknowledges RCN project ORGANIC (239965). The authors want to thank Alf Grini for his technical assistance in setting up and running the model experiments and the rest of the EXPECT team.

Edited by: Joachim Segschneider

Reviewed by: two anonymous referees

\section{References}

Ahlm, L., Jones, A., Stjern, C. W., Muri, H., Kravitz, B., and Kristjánsson, J. E.: Marine cloud brightening - as effective without clouds, Atmos. Chem. Phys., 17, 13071-13087, https://doi.org/10.5194/acp-17-13071-2017, 2017.

Alterskjær, K., Kristjansson, J. E., Boucher, O., Muri, H., Niemeier, U., Schmidt, H., Schulz, M., and Timmreck, C.: Sea-salt injections into the low-latitude marine boundary layer: The transient response in three Earth system models, J. Geophys. Res.-Atmos., 118, 12195-12206, https://doi.org/10.1002/2013jd020432, 2013.
Aswathy, V. N., Boucher, O., Quaas, M., Niemeier, U., Muri, H., Mülmenstädt, J., and Quaas, J.: Climate extremes in multi-model simulations of stratospheric aerosol and marine cloud brightening climate engineering, Atmos. Chem. Phys., 15, 9593-9610, https://doi.org/10.5194/acp-15-9593-2015, 2015.

Bala, G., Caldeira, K., Nemani, R., Cao, L., Ban-Weiss, G., and Shin, H.-J. Albedo enhancement of marine clouds to counteract global warming: impacts on the hydrological cycle, Clim. Dynam., 37, 915-931, https://doi.org/10.1007/s00382-010-0868-1, 2011.

Bentsen, M., Bethke, I., Debernard, J. B., Iversen, T., Kirkevåg, A., Seland, Ø., Drange, H., Roelandt, C., Seierstad, I. A., Hoose, C., and Kristjánsson, J. E.: The Norwegian Earth System Model, NorESM1-M - Part 1: Description and basic evaluation of the physical climate, Geosci. Model Dev., 6, 687-720, https://doi.org/10.5194/gmd-6-687-2013, 2013.

Bickel, J. and Lane, L.: An Analysis of Climate Engineering as a Response to Climate Change, Copenhagen Consensus Center, Frederiksberg, Denmark, 2009.

Bopp, L., Resplandy, L., Orr, J. C., Doney, S. C., Dunne, J. P., Gehlen, M., Halloran, P., Heinze, C., Ilyina, T., Séférian, R., Tjiputra, J., and Vichi, M.: Multiple stressors of ocean ecosystems in the 21st century: projections with CMIP5 models, Biogeosciences, 10, 6225-6245, https://doi.org/10.5194/bg-106225-2013, 2013.

Buchholz, F., Werner, T., and Buchholz, C.: First observation of krill spawning in the high Arctic Kongsfjorden, west Spitsbergen, Polar Biol., 35, 1273-1279, https://doi.org/10.1007/s00300012-1186-3, 2012.

Crook, J. A., Jackson, L. S., Osprey, S. M., and Forster, P. M.: A comparison of temperature and precipitation responses to different Earth radiation management geoengineering schemes, J. Geophys. Res.-Atmos., 120, 9352-9373, https://doi.org/10.1002/2015jd023269, 2015.

Crutzen, P. J.: Albedo enhancement by stratospheric sulfur injections: A contribution to resolve a policy dilemma?, Climatic Change, 77, 211-219, https://doi.org/10.1007/s10584-006-9101y, 2006.

Fossheim, M., Primicerio, R., Johannesen, E., Ingvaldsen, R. B., Aschan, M. M., and Dolgov, A. V.: Recent warming leads to a rapid borealization of fish communities in the Arctic, Nat. Clim. Change, 5, 673-677, https://doi.org/10.1038/nclimate2647, 2015.

Friedlingstein, P., Cox, P., Betts, R., Bopp, L., von Bloh, W., Brovkin, V., Cadule, P., Doney, S., Eby, M., Fung, I., Bala, G., John, J., Jones, C., Joos, F., Kato, T., Kawamiya, M., Knorr, W., Kindsay, K., Matthews, H. D., Raddatz, T., Rayner, P., Reick, C., Roeckner, E., Schnitzler, K.-G., Schnur, R., Strassmann, K., Weaver, A. J., Yoshikawa, C., and Zeng, N.: Climate-Carbon Cycle Feedback Analysis: Results from the C4MIP Model Intercomparison, J. Climate, 19, 3337-3353, 2006.

Hardman-Mountford, N. J., Polimene, L., Hirata, T., Brewin, R. J. W., and Aiken, J.: Impacts of light shading and nutrient enrichment geo-engineering approaches on the productivity of a stratified, oligotrophic ocean ecosystem, J. R. Soc. Interface, 10, 20130701, https://doi.org/10.1098/rsif.2013.0701, 2013.

Henson, S. A., Beaulieu, C., Ilyina, T., John, J. G., Long, M., Séférian, R., Tjiputra, J., and Sarmiento, J. L.: Rapid emergence of climate change in environmental 
drivers of marine ecosystems, Nat. Commun., 8, 14682, https://doi.org/10.1038/ncomms14682, 2017.

IPCC: Climate Change 2013: The Physical Science Basis. Contribution of Working Group I to the Fifth Assessment Report of the Intergovernmental Panel on Climate Change, edited by: Stocker, T. F., Qin, D., Plattner, G.-K., Tignor, M., Allen, S. K., Boschung, J., Nauels, A., Xia, Y., Bex, V., and Midgley, P. M., Cambridge University Press, Cambridge, UK and New York, NY, USA, 1535 pp., 2013.

Irvine, P. J., Kravitz, B., Lawrence, M. G., and Muri, H.: An overview of the Earth system science of solar geoengineering, WIREs Climate Change, 7, 815-833, https://doi.org/10.1002/wcc.423, 2016.

Irvine, P. J., Kravitz, B., Lawrence, M. G., Gerten, D., Caminade, C., Gosling, S. N., Hendy, E., Kassie, B., Kissling, W. D., Muri, H., Oschlies, A., and Smith, S. J.: Towards a comprehensive climate impacts assessment of solar geoengineering, Earth's Future, 5, 96-106, https://doi.org/10.1002/2016EF000389, 2017.

Latham, J.: Control of Global Warming, Nature, 347, 339-340, https://doi.org/10.1038/347339b0, 1990.

Ma, X., von Salzen, K., and Li, J.: Modelling sea salt aerosol and its direct and indirect effects on climate, Atmos. Chem. Phys., 8, 1311-1327, https://doi.org/10.5194/acp-8-1311-2008, 2008.

Maier-Reimer, E., Kriest, I., Segschneider, J., and Wetzel, P.: The Hamburg Oceanic Carbon Cycle Circulation model HAMOCC5.1, Max Planck Institute for Meteorology, Hamburg, Germany, 2005.

Matthews, H. D., Cao, L., and Caldeira, K.: Sensitivity of ocean acidification to geoengineered climate stabilization, Geophys. Res. Lett., 36, L10706, https://doi.org/10.1029/2009g1037488, 2009.

Mitchell, D. L. and Finnegan, W.: Modification of cirrus clouds to reduce global warming, Environ. Res. Lett., 4, 045102, https://doi.org/10.1088/1748-9326/4/4/045102, 2009.

Mora, C., Wei, C. L., Rollo, A., Amaro, T., Baco, A. R., Billett, D., Bopp, L., Chen, Q., Collier, M., Danovaro, R., Gooday, A. J., Grupe, B. M., Halloran, P. R., Ingels, J., Jones, D. O. B., Levin, L. A., Nakano, H., Norling, K., Ramirez-Llodra, E., Rex, M., Ruhl, H. A., Smith, C. R., Sweetman, A. K., Thurber, A. R., Tjiputra, J. F., Usseglio, P., Watling, L., Wu, T. W., and Yasuhara, M.: Biotic and Human Vulnerability to Projected Changes in Ocean Biogeochemistry over the 21st Century, Plos Biol., 11, e1001682, https://doi.org/10.1371/journal.pbio.1001682, 2013.

Muri, H., Kristjansson, J. E., Storelvmo, T., and Pfeffer, M. A.: The climatic effects of modifying cirrus clouds in a climate engineering framework, J. Geophys. Res.-Atmos., 119, 4174-4191, https://doi.org/10.1002/2013jd021063, 2014

Muri, H., Tjiputra, J. Otterå, O. H., Adakudlu, M., Lauvset, S. K., Grini, A., Schulz, M., and Kristjansson, J. E.: Climate response to aerosol injection geoengineering: a multi-method comparison, J. Climate, in review, 2017.

Niemeier, U. and Timmreck, C.: What is the limit of climate engineering by stratospheric injection of $\mathrm{SO}_{2}$ ?, Atmos. Chem. Phys., 15, 9129-9141, https://doi.org/10.5194/acp-159129-2015, 2015.

Niemeier, U., Schmidt, H., Alterskjaer, K., and Kristjansson, J. E.: Solar irradiance reduction via climate engineering: Impact of different techniques on the energy balance and the hy- drological cycle, J. Geophys. Res.-Atmos., 118, 11905-11917, https://doi.org/10.1002/2013jd020445, 2013.

Partanen, A.-I., Kokkola, H., Romakkaniemi, S., Kerminen, V. M., Lehtinen, K. E. J., Bergman, T., Arola, A., and Korhonen, H.: Direct and indirect effects of sea spray geoengineering and the role of injected particle size, J. Geophys. Res., 117, D02203, https://doi.org/10.1029/2011JD016428, 2012.

Partanen, A.-I., Keller, D. P., Korhonen, H., and Matthews, H. D.: Impacts of sea spray geoengineering on ocean biogeochemistry, Geophys. Res. Lett., 43, 7600-7608, https://doi.org/10.1002/2016gl070111, 2016.

Pörtner, H.-O., Karl, D. M., Boyd, P. W., Cheung, W. W. L., LluchCota, S. E., Nojiri, Y., Schmidt, D. N., and Zavialov, P. O.: Ocean systems, in: Climate Change 2014: Impacts, Adaptation, and Vulnerability. Part A: Global and Sectoral Aspects. Contribution of Working Group II to the Fifth Assessment Report of the Intergovernmental Panel on Climate Change, edited by: Field, C. B., Barros, V. R., Dokken, D. J., Mach, K. J., Mastrandrea, M. D., Bilir, T. E., Chatterjee, M., Ebi, K. L., Estrada, Y. O., Genova, R. C., Girma, B., Kissel, E. S., Levy, A. N., MacCracken, S., Mastrandrea, P. R., and White, L. L., 411-484, Cambridge University Press, Cambridge, UK and New York, NY, USA, 2014.

Riahi, K., Rao, S., Krey, V., Cho, C. H., Chirkov, V., Fischer, G., Kindermann, G., Nakicenovic, N., and Rafaj, P.: RCP 8.5 - A scenario of comparatively high greenhouse gas emissions, Climatic Change, 109, 33-57, https://doi.org/10.1007/s10584-0110149-y, 2011.

Six, K. D. and Maier-Reimer, E.: Effects of plankton dynamics on seasonal carbon fluxes in an ocean general circulation model, Global Biogeochem. Cy., 10, 559-583, https://doi.org/10.1029/96gb02561, 1996.

Stjern, C. W., Muri, H., Ahlm, L., Boucher, O., Cole, J. N. S., Ji, D., Jones, A., Haywood, J., Kravitz, B., Lenton, A., Moore, J. C., Niemeier, U., Phipps, S. J., Schmidt, H., Watanabe, S., and Kristjánsson, J. E.: Response to marine cloud brightening in a multi-model ensemble, Atmos. Chem. Phys. Discuss., https://doi.org/10.5194/acp-2017-629, in review, 2017.

Storelvmo, T., Kristjansson, J. E., Muri, H., Pfeffer, M., Barahona, D., and Nenes, A.: Cirrus cloud seeding has potential to cool climate, Geophys. Res. Lett., 40, 178-182, https://doi.org/10.1029/2012g1054201, 2013.

Teller, E., Hyde, R., Ishikawa, M., Nuckolls, J., and Wood, L.: Active Stabilization of Climate: Inexpensive, Lowrisk, near-Term Options for Preventing Global Warming and Ice Ages Via Technologically Varied Solar Radiative Forcing, Lawrence Livermore National Library, 2003.

Thomson, A. M., Calvin, K. V., Smith, S. J., Kyle, G. P., Volke, A., Patel, P., Delgado-Arias, S., Bond-Lamberty, B., Wise, M. A., Clarke, L. E., and Edmonds, J. A.: RCP4.5: a pathway for stabilization of radiative forcing by 2100 , Climatic Change, 109, 77-94, https://doi.org/10.1007/s10584-011-0151-4, 2011.

Tjiputra, J. F., Roelandt, C., Bentsen, M., Lawrence, D. M., Lorentzen, T., Schwinger, J., Seland, Ø., and Heinze, C.: Evaluation of the carbon cycle components in the Norwegian Earth System Model (NorESM), Geosci. Model Dev., 6, 301-325, https://doi.org/10.5194/gmd-6-301-2013, 2013.

Tjiputra, J. F., Grini, A., and Lee, H.: Impact of idealized future stratospheric aerosol injection on the large scale ocean 
and land carbon cycles, J. Geophys. Res.-Biogeo., 120, 2-27, https://doi.org/10.1002/2015jg003045, 2016.

Wanninkhof, R.: Relationship between wind speed and gas exchange over the ocean, J. Geophys. Res., 97, 7373-7382, 1992.

Weisenstein, D. K., Keith, D. W., and Dykema, J. A.: Solar geoengineering using solid aerosol in the stratosphere, Atmos. Chem. Phys., 15, 11835-11859, https://doi.org/10.5194/acp-15-118352015, 2015

Wigley, T. M. L.: A combined mitigation/geoengineering approach to climate stabilization, Science, 314, 452-454, https://doi.org/10.1126/science.1131728, 2006.
Zeller, D., Palomares, M. L. D., Tavakolie, A., Ang, M., Belhabib, D., Cheung, W. W. L., Lam, V. W. Y., Sy, E., Tsui, G., Zylich, K., and Pauly, D.: Still catching attention: Sea Around Us reconstructed global catch data, their spatial expression and public accessibility, Mar. Policy, 70, 145-152, https://doi.org/10.1016/j.marpol.2016.04.046, 2016. 